\title{
Epidemiological and economic burden of metabolic syndrome and its consequences in patients with hypertension in Germany, Spain and Italy; a prevalence-based model
}

Jürgen Scholze ${ }^{1 *}$, Eduardo Alegria ${ }^{2}$, Claudio Ferri ${ }^{3}$, Sue Langham ${ }^{4}$, Warren Stevens ${ }^{5}$, David Jeffries ${ }^{6}$, Kerstin Uhl-Hochgraeber ${ }^{7}$

\begin{abstract}
Background: The presence of metabolic syndrome in patients with hypertension significantly increases the risk of cardiovascular disease, type 2 diabetes and mortality. Our aim is to estimate the epidemiological and economic burden to the health service of metabolic syndrome in patients with hypertension in three European countries in 2008 and 2020.

Methods: An age, sex and risk group structured prevalence based cost of illness model was developed using the United States Adult Treatment Panel III of the National Cholesterol Education Program criteria to define metabolic syndrome. Data sources included published information and public use databases on disease prevalence, incidence of cardiovascular events, prevalence of type 2 diabetes, treatment patterns and cost of management in Germany, Spain and Italy.

Results: The prevalence of hypertension with metabolic syndrome in the general population of Germany, Spain and Italy was 36\%, 11\% and 10\% respectively. In subjects with hypertension $61 \%, 22 \%$ and $21 \%$ also had metabolic syndrome. Incident cardiovascular events and attributable mortality were around two fold higher in subjects with metabolic syndrome and prevalence of type 2 diabetes was around six-fold higher. The economic burden to the health service of metabolic syndrome in patients with hypertension was been estimated at $€ 24,427, € 1,900$ and $€ 4,877$ million in Germany, Spain and Italy and forecast to rise by 59\%, 179\% and 157\% respectively by 2020 . The largest components of costs included the management of prevalent type 2 diabetes and incident cardiovascular events. Mean annual costs per hypertensive patient were around three-fold higher in subjects with metabolic syndrome compared to those without and rose incrementally with the additional number of metabolic syndrome components present.

Conclusion: The presence of metabolic syndrome in patients with hypertension significantly inflates economic burden and costs are likely to increase in the future due to an aging population and an increase in the prevalence of components of metabolic syndrome.
\end{abstract}

\section{Background}

High blood pressure is a leading cause of death and disability causing $13.5 \%$ of the world's premature death and $6 \%$ of its disability. Half of all strokes and ischemic

\footnotetext{
* Correspondence: juergen.scholze@charite.de 'Department of Medicine, Outpatient Clinic, CCM, ChariteUniversitatsmedizin Berlin, Luisenstrasse 11-13, 10117 Berlin, Germany Full list of author information is available at the end of the article
}

heart disease can be attributed to high blood pressure [1]. This situation shows no sign of abating. Obesity, a major risk factor for hypertension, has reached pandemic proportions [2] and research shows that around two thirds of the prevalence of hypertension is directly attributable to obesity [3]. Along with obesity, other independent cardiometabolic abnormalities, such as dyslipidaemia, hypertriglyceridaemia and glucose 
metabolism disturbances have also been found to cluster together. Such groupings of risk factors for cardiovascular disease in the same hypertensive individual occur together more often than would be expected by chance alone, giving rise to a clinical entity that has been termed metabolic syndrome (MetS) [4]. The syndrome has been shown to significantly increase the risk of cardiovascular disease, type 2 diabetes and mortality [5-8]. In patients with hypertension it doubles the relative risk of cardiovascular disease [9-11] and triples the relative risk of type 2 diabetes [12]. Moreover, the risk increases with the number of MetS components present $[10,13]$. As there are 16 different conceivable combinations of risk factors that could be diagnosed as MetS not all can be weighted equally in terms of their impact on risk and for some combinations this increase in risk is controversial. However, what is known for sure is that the coexistence of hypertension disproportionately increases the risk of cardiovascular disease [14].

However, there is much debate as to whether MetS should be treated as a clinical entity in general practice or whether physicians should concentrate on treating individual risk factors. The primary purpose for diagnosing MetS in general practice is to identify patients who are at high long-term risk of developing cardiovascular disease and type 2 diabetes and who require lifestyle and/or pharmacological therapies to reduce this risk. Recent European guidelines on the management of patients with arterial hypertension consider those with hypertension and MetS as a special condition suggesting a different therapeutic approach compared to patients with hypertension alone [15]. Such recommendations are based on a number of evidence-based observations. In a position statement the European Society of Hypertension pointed out that in patients with hypertension and MetS the overall cardiovascular risk may be greater than the sum of its identifiable components and that MetS components are often defined by values lower than those defined in various individual risk factor guidelines which may lead to many patients with high cardiovascular risk not being identified [16]. They also point out that MetS risk factors are relatively easily identified in clinical practice.

The clinical utility of diagnosing MetS in general practice has been hampered by the inconsistency of the diagnostic criteria available. Some definitions appear to be better than others at identifying high risk patients in Europe. In studies using both the International Diabetes Federation criteria and those developed by the United States Adult Treatment Panel III of the National Cholesterol Education Program (ATP III) a much higher prevalence of MetS was identified by the International Diabetes Federation criteria $[17,18]$ but these criteria led to much lower predictive power for coronary events than the ATP III criteria [19]. This suggests that currently the ATP III criteria are the most appropriate for European populations given that excessive over-diagnosing of the syndrome would subject the health service to unnecessary budget pressures.

Relatively little is known about the epidemiological burden of MetS in patients with hypertension in the general population in Europe. Using ATP III criteria, European population studies suggest that the prevalence is around $8 \%$ to $13 \%$ [20-22]. The reported proportion of hypertensive patients that have MetS is wide-ranging. Population-based studies suggest the proportion is around $20 \%$ to $40 \%$ [20-23]. Primary care studies report that a fifth and up to just over a half of hypertension patients can be diagnosed with MetS [13,17,24-27].

No studies have assessed the economic burden of MetS in patients with hypertension. In order to fill this gap this study aims to model the health care costs of hypertension in three European countries (Germany, Spain and Italy) in 2008 and 2020 and to assess how the consequences of MetS in terms of associated type 2 diabetes and the increase in cardiovascular events impacts on this economic burden.

\section{Methods \\ Overview}

This study uses a prevalence-based approach that combined the demographics of the population with hypertension and MetS prevalence rates, incidence of cardiovascular disease, prevalence of type 2 diabetes and healthcare costs into a cost of hypertension and MetS model. A comprehensive literature review was conducted to identify inputs and data sources included national surveys, IMS Health Pharmaceuticals Sales data and published information. The model and the assumptions used have been described in detail elsewhere [28].

Briefly we developed a prevalence-based model from the perspective of the health service (Figure 1). MetS was defined according to modified ATP III criteria, where an individual is defined as having MetS if they have three out of five diagnostic criteria: Abdominal obesity (waist; males $>102 \mathrm{~cm}$, females $>88 \mathrm{~cm}$ ), hypertension ( $\geq 140 / 90 \mathrm{~mm} \mathrm{Hg}$ ), low high-density lipoprotein (HDL) cholesterol (males $<40 \mathrm{mg} / \mathrm{dL}$, females $<50 \mathrm{mg} /$ $\mathrm{dL})$, high triglycerides $(\geq 150 \mathrm{mg} / \mathrm{dL})$ and impaired fasting glucose ( $\geq 110 \mathrm{mg} / \mathrm{dL}$ or known diabetes) [29]. We modified the criteria in relation to blood pressure from $\geq 135 / 85 \mathrm{~mm} \mathrm{Hg}$ to $\geq 140 / 90 \mathrm{~mm} \mathrm{Hg}$ for two reasons; first all epidemiological publications and databases used to develop the model defined hypertension as blood pressure of $\geq 140 / 90 \mathrm{~mm} \mathrm{Hg}$ and second, because current European and U.S. guidelines use this definition as the treatment threshold for antihypertensive medication $[15,30]$. 


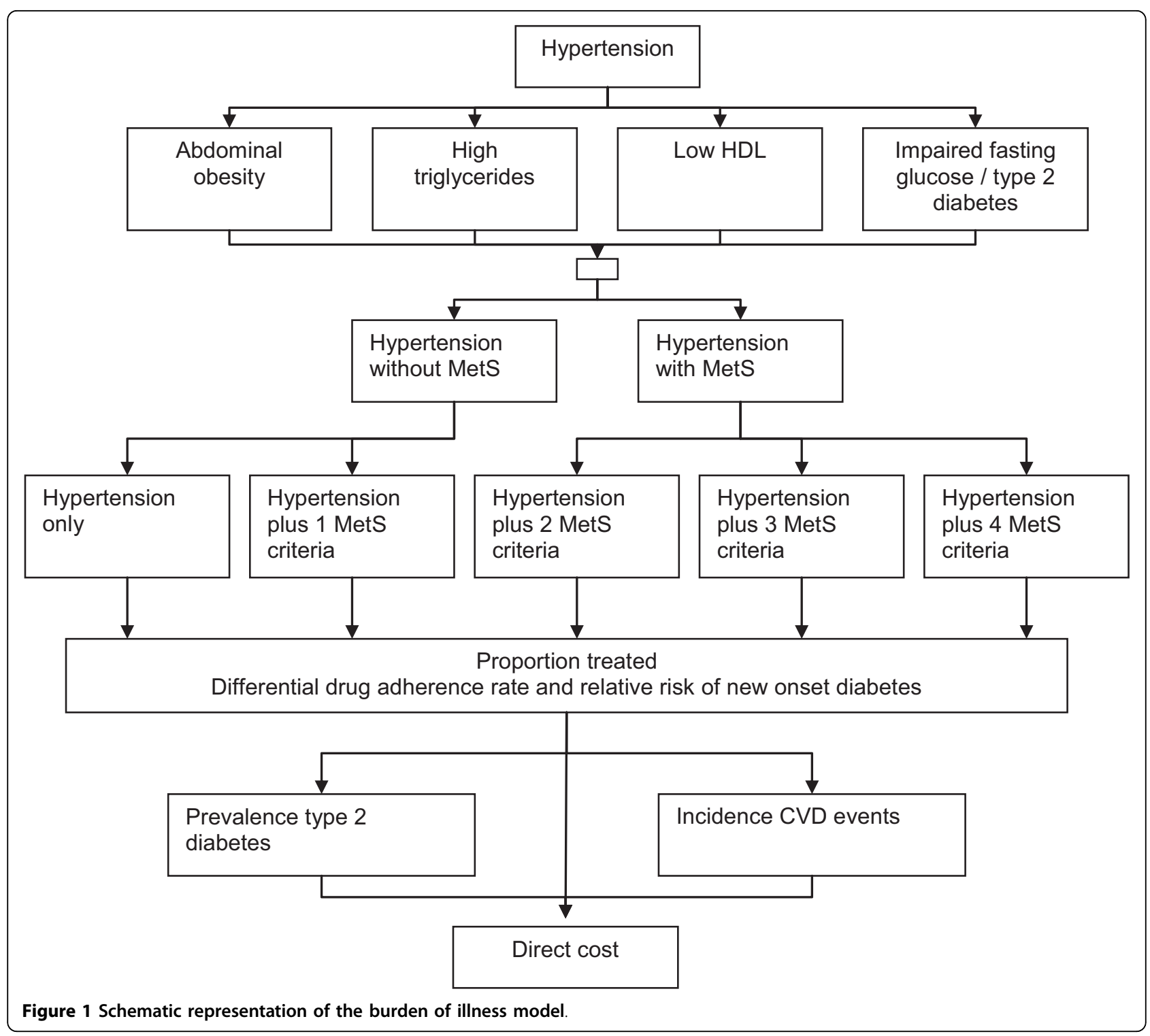

The model considered all patients in Germany, Spain and Italy over the age of 20 years. Two sets of risk groups were defined, totalling seven risk categories. Risk was stratified first into two categories - those patients with hypertension and MetS and those without - where MetS was indicated by the hypertensive individual having at least two other ATP III criteria, and second into five risk categories - those patients with hypertension only, hypertension plus one other ATP III criteria, hypertension plus two other, hypertension plus three other and hypertension plus four other ATP III criteria (Figure 1). In order to breakdown the hypertension population data into these risk groups we analysed the United States National Health and Nutrition Examination Survey (NHANES) public use database (2000) to assess the conditional structure for the five components of MetS and applied this conditional structure to country-specific prevalence data.

\section{Data sources}

Prevalence data were sourced from a national survey in Germany [31] and published epidemiological studies in Spain $[17,32]$ and Italy $[22,33]$. In order to estimate the future prevalence up to 2020 compound annual growth rates (CAGRs) were derived from the literature [34] or a multiyear evaluation of the NHANES public use database.

Each risk group was divided into those who receive antihypertensive drug treatment and those who don't. For the treated group the proportion and cost of hypertensive subjects treated with each antihypertensive drug class (monotherapy and combination therapy for 
angiotensin II receptor blockers (ARBs), angiotensin converting enzyme (ACE) inhibitors, calcium channel blockers, diuretics and beta-blockers) were derived from an analysis of IMS Health pharmaceutical national sales data for all main antihypertensive drug classes prescribed in 2007 to patients with an ICD-10 code for hypertension. Treated patients were also assumed to have associated costs for primary care visits to the clinic for check-ups, tests and assessment of hypertensive medication which were derived from country specific publications [35-37]. For the treated group the model took into account the differential adherence rate [38] and relative risk of treatment-related new onset diabetes between the drug classes [39].

For both treated and untreated patients the incidence of cardiovascular events and prevalence of type 2 diabetes and their associated costs were estimated. Cardiovascular events included acute myocardial infarction, congestive heart failure, unstable angina, stroke and death. Incidence and costs of events were derived from the literature $[11,13,40-45]$. The prevalence of type 2 diabetes in the hypertensive population was derived from a European national survey [31] and costs derived from published country-specific data [46].

The cost data in the model takes the viewpoint of the health service and includes hypertension drug costs, management of hypertension in primary care and costs associated with the treatment and management of cardiovascular events and type 2 diabetes. The cost of each of these elements was calculated by multiplying the quantity of the resource used or the number of events with the unit price. All costs were inflated to 2008 prices and presented in Euros.

\section{Analyses}

The burden of illness model was created in Access. The Access model generated epidemiological numbers and costs which were then exported to excel for analysis. The model was quality controlled by cross-checking epidemiological and cost data with other published reports.

To address uncertainty around the mean in the overall cost of illness estimate, we conducted a univariate sensitivity analysis, where one factor at a time was varied while keeping all other factors constant at their base-case value. We assessed the impact on cost-of-illness of; only including incident rather than prevalent type 2 diabetes, varying the continuation rate, drug cost, cardiovascular cost and type 2 diabetes cost by plus and minus $20 \%$; and applying a discount rate of $3 \%$ to future costs.

\section{Results}

\section{Prevalence and risk groups}

The prevalence of hypertension with MetS in the general population of Germany, Spain and Italy was $36 \%$,
$11 \%$ and $10 \%$ respectively in 2008 . In Germany of all subjects with hypertension over half (61\%) complied with the ATP III criteria for MetS. In Spain and Italy this proportion was much lower with $22 \%$ and $21 \%$ respectively. By 2020 the proportion of the hypertensive population with MetS was forecast to increase to $78 \%$, $45 \%$ and $43 \%$ in Germany, Spain and Italy respectively giving a prevalence in the general population of hypertension with MetS of $48 \%$ in Germany and 22\% in Spain and Italy. Germany had a higher proportion of hypertensive subjects with three or four other components of MetS (36\%) compared to Spain (8\%) and Italy (7\%) (figure 2).

Figure 3 outlines the prevalence of each individual MetS component in patients with hypertension in 2008 and 2020. The most prevalent component was abdominal obesity which reached a prevalence of $62 \%, 40 \%$ and $44 \%$ in hypertensive patients in Germany, Spain and Italy respectively in 2008. This was followed by high tryiglycerides, and then impaired fasting glucose. All MetS components were forecast to rise with the prevalence of abdominal obesity and impaired fasting glucose increasing the most.

\section{Consequences of disease}

The incidence of cardiovascular disease and mortality was around two-fold higher in hypertensive subjects with MetS compared to those without in all three countries. The prevalence of type 2 diabetes was around six fold higher in subjects with MetS (table 1). The incidence of cardiovascular disease and mortality and the prevalence of type 2 diabetes increased incrementally with each additional component of MetS. The total number of cardiovascular events, deaths and cases of type 2 diabetes are forecast to rise over $100 \%$ in Spain and Italy respectively between 2008 and 2020 and by around $50 \%$ in Germany (table 1 ).

\section{Costs}

Table 2 details the total annual cost-of-illness of hypertension with and without MetS in 2008 and 2020 in Germany, Spain and Italy. Total annual costs of hypertension with MetS amounted to $€ 24,427, € 1,909$ and $€ 4,877$ million respectively in Germany, Spain and Italy in 2008. These costs represented $82 \%, 42 \%$ and $45 \%$ of the total annual costs of hypertension. By 2020, keeping costs set at 2008 prices, these annual costs of hypertension with MetS were forecast to rise by $59 \%, 179 \%$, $157 \%$ in Germany, Spain and Italy respectively (table 2).

The largest component of the total annual cost of hypertensive patients with MetS was the treatment and management of the consequence of disease rather than the management of hypertension itself including physician and drug costs. Prevalent type 2 diabetes and 


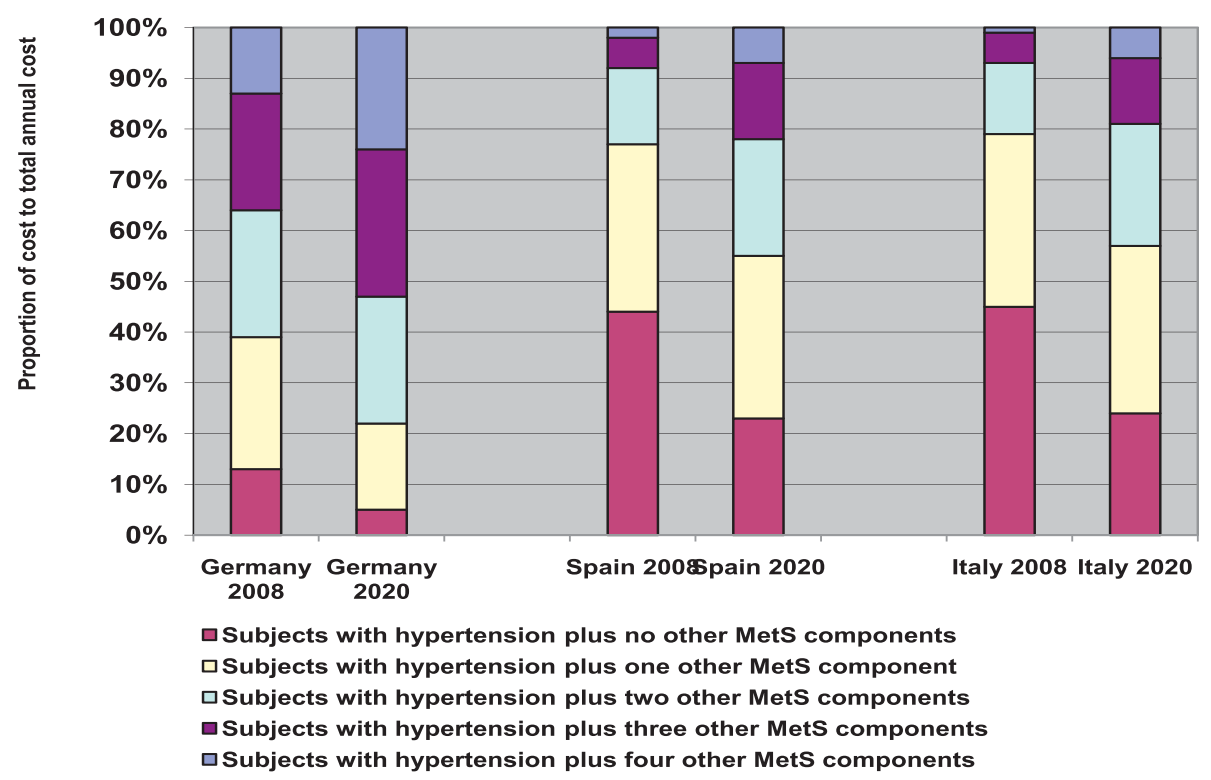

Figure 2 Proportion of the hypertensive population > 20 years within each risk group; 2008-2020.

incident cardiovascular disease constituted $67 \%$ and $22 \%$ of total costs respectively in Germany in 2008 (figure 4). In Spain these proportions were $50 \%$ and $37 \%$ and in Italy were $71 \%$ and $17 \%$. Hypertension drug costs and physician costs relating to the management of hypertension constituted the smallest proportion of total costs in all countries (figure 4).

Mean annual costs per hypertensive patient were around three-fold higher in subjects with MetS compared to those without and rose incrementally with the additional number of MetS components present (figure $5)$. The greatest increment in per patient costs was from no metabolic components present to one where there was a two-fold increase after which the costs increased by around 1.2 to 1.8 fold with each additional component.

\section{Sensitivity analysis}

A number of sensitivity analyses were conducted (table 3). The total annual cost-of-illness of hypertension, with and without the presence of MetS did not vary significantly from the base case, with the exception of only including cases of incident or new onset diabetes rather than prevalent type 2 diabetes. In particular, in Germany by only including incident type 2 diabetes reduced the cost of hypertension with MetS from $€ 24,427$ million to $€ 8,753$ million. There was also a greater degree of variation in total costs when cardiovascular and type 2

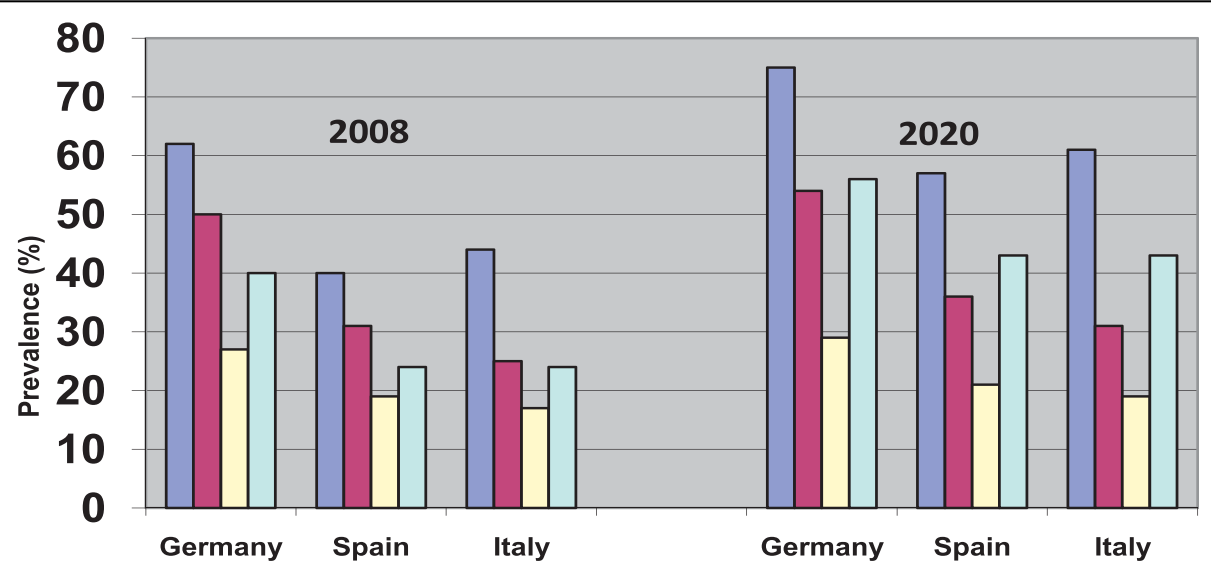

$\square$ Abdominal obesity $\square$ High triglycerides $\square$ Low HDL $\square$ Impaired fasting glucose

Figure 3 Prevalence of individual components of MetS in patients with hypertension; 2008 and 2020 
Table 1 Annual number and event rate per 1,000 hypertensive patients of incident cases of cardiovascular disease, mortality and prevalent cases of type 2 diabetes; 2008 and 2020

\begin{tabular}{|c|c|c|c|c|c|c|}
\hline & \multicolumn{2}{|c|}{ Germany } & \multicolumn{2}{|c|}{ Spain } & \multicolumn{2}{|c|}{ Italy } \\
\hline & No. events & Event rate* & No. events & Event rate* & No. events & Event rate* \\
\hline \multicolumn{7}{|c|}{ Annual incidence of cardiovascular events } \\
\hline \multicolumn{7}{|l|}{2008} \\
\hline MetSt & 583,500 & 27 & 74,600 & 25 & 103,300 & 24 \\
\hline No MetS‡ & 188,500 & 14 & 134,000 & 13 & 202,500 & 13 \\
\hline \multicolumn{7}{|l|}{2020} \\
\hline MetSt & 889,500 & 29 & 208,300 & 27 & 267,800 & 25 \\
\hline No MetSł & 124,400 & 14 & 132,200 & 14 & 189,900 & 13 \\
\hline \multicolumn{7}{|c|}{ Annual incidence of mortality } \\
\hline \multicolumn{7}{|l|}{2008} \\
\hline MetS† & 64,000 & 3.00 & 14,800 & 2.74 & 11,300 & 2.64 \\
\hline No MetSł & 20,600 & 1.49 & 8,200 & 1.45 & 22,400 & 1.40 \\
\hline \multicolumn{7}{|l|}{2020} \\
\hline MetS† & 97,800 & 3.17 & 22,800 & 2.90 & 29,300 & 2.78 \\
\hline No MetSł & 13,600 & 1.52 & 14,500 & 1.50 & 20,800 & 1.50 \\
\hline \multicolumn{7}{|c|}{ Annual prevalence of type 2 diabetes } \\
\hline \multicolumn{7}{|l|}{2008} \\
\hline MetS† & $5,287,600$ & 248 & 834,500 & 281 & $1,313,300$ & 308 \\
\hline No MetS $\ddagger$ & 627,300 & 45 & 515,100 & 51 & 823,700 & 52 \\
\hline \multicolumn{7}{|l|}{2020} \\
\hline MetS† & $8,676,100$ & 281 & $2,364,500$ & 301 & $3,390,200$ & 322 \\
\hline No MetSł & 510,300 & 57 & 703,400 & 73 & $1,021,600$ & 71 \\
\hline
\end{tabular}

* Event rate per 1000, $\uparrow$ hypertension patients with MetS, $\neq$ hypertension patients without MetS.

diabetes costs were varied by plus or minus $20 \%$ than when drug costs and continuation rates were varied. We also assessed the impact of applying a discount rate of $3 \%$ to future costs. This would reduce the total annual cost of hypertension in 2020 from $€ 42,769$ million to $€ 29,997$ million in Germany; from $€ 8,180$ million to $€ 5,737$ million in Spain; and from $€ 18,710$ million to $€ 13,123$ million in Italy.

\section{Discussion}

The results of this modelling study suggest that the presence of MetS in patients with hypertension significantly inflates the cost of illness due to the increase in cardiovascular events and cases of type 2 diabetes. These costs rise incrementally with the additional number of MetS components present. In Germany hypertensive patients with MetS account for over $60 \%$ of all hypertensive patients and contribute to $80 \%$ of the costs. In Spain and Italy they account for nearly a quarter of the hypertensive population and contribute to nearly half of the costs. The much higher prevalence in Germany can be explained by the country having one of the highest rates of abdominal obesity in Europe [47]. Mean annual costs per patient for those with MetS are two to three times higher than for those without. Antihypertensive drug costs make up less than $10 \%$ of overall costs of care in this high risk patient group with the management and treatment of cardiovascular events and type 2 diabetes accounting for the majority of costs.

These costs are set to rise in the future as the proportion of the population over the age of 50 years grows and the prevalence of the components of MetS increases. The most prevalent component of MetS in patients with hypertension is abdominal obesity which has reached epidemic proportions in Europe and currently shows no sign of slowing down [48].

This study used a prevalence-based modelling approach to estimate cost-of-illness and therefore is subject to a number of assumptions. Although efforts were made to ensure the best sources of data available to date were used in the model, as the published literature in this area is still relatively limited and national databases do not provide all appropriate data required to estimate epidemiological burden [49], there were a number of data gaps. As with all models that require some assumptions to be made an element of caution is required when interpreting the results. The assumptions used in this model are described in detail elsewhere [28]. For example we used a United States database to develop our conditional probability matrix which provided data on the probability of hypertensive subjects having no other MetS components, one, two, three or 
Table 2 Annual cost-of-illness (Euros, millions) of hypertension and the proportion of costs attributable to MetS; 2008 and 2020

\begin{tabular}{|c|c|c|c|c|c|}
\hline & \multicolumn{5}{|c|}{ Annual costs } \\
\hline & Drug $^{1}$ & Physician $^{2}$ & $C V D^{3}$ & $\begin{array}{r}\text { Type } 2 \\
\text { diabetes }^{4}\end{array}$ & Total \\
\hline \multicolumn{6}{|l|}{2008} \\
\hline \multicolumn{6}{|l|}{ Germany } \\
\hline With MetS† & 628 & 1,952 & 5,265 & 16,582 & 24,427 \\
\hline $\begin{array}{l}\text { Without } \\
\text { MetS } \neq\end{array}$ & 407 & 1,264 & 1,703 & 1,967 & 5,341 \\
\hline \multicolumn{6}{|l|}{ Spain } \\
\hline With MetS & 116 & 126 & 699 & 968 & 1,909 \\
\hline $\begin{array}{l}\text { Without } \\
\text { MetS }\end{array}$ & 397 & 432 & 1,256 & 597 & 2,682 \\
\hline \multicolumn{6}{|l|}{ Italy } \\
\hline With MetS & 258 & 330 & 817 & 3,472 & 4,877 \\
\hline $\begin{array}{l}\text { Without } \\
\text { MetS }\end{array}$ & 958 & 1,222 & 1,599 & 2,178 & 5,957 \\
\hline \multicolumn{6}{|l|}{2020} \\
\hline \multicolumn{6}{|l|}{ Germany } \\
\hline With MetSt & 901 & 2,820 & 8,026 & 27,208 & 38,955 \\
\hline $\begin{array}{l}\text { Without } \\
\text { MetS‡ }\end{array}$ & 270 & 817 & 1,124 & 1,600 & 3,811 \\
\hline \multicolumn{6}{|l|}{ Spain } \\
\hline With MetS & 301 & 333 & 1,952 & 2,743 & 5,329 \\
\hline $\begin{array}{l}\text { Without } \\
\text { MetS }\end{array}$ & 384 & 412 & 1,240 & 816 & 2,852 \\
\hline \multicolumn{6}{|l|}{ Italy } \\
\hline With MetS & 629 & 813 & 2,117 & 8,964 & 12,523 \\
\hline $\begin{array}{l}\text { Without } \\
\text { MetS }\end{array}$ & 877 & 1,109 & 1,500 & 2,701 & 6,187 \\
\hline
\end{tabular}

CVD-cardiovascular disease.

† hypertension patients with MetS, ₹ hypertension patients without MetS. 'Drug costs relate to antihypertensive treatments only, ${ }^{2}$ physician costs relate to visits to the clinic as a result of hypertension for check-ups and assessment of antihypertensive medication, ${ }^{3} \mathrm{CVD}$ costs relate to ambulatory and hospitalisation costs for the management of each event, ${ }^{4}$ type 2 diabetes costs relate to the management of each patients and the costs of non-CVD related complications. four and the probability of each combination occurring in each age and sex group. These probabilities were applied to country-specific prevalence data to breakdown individuals into each risk group. We have no reason to assume that such conditional structures would be different between the U.S. and the three European countries as the clustering of individual MetS risk factors is unlikely to be significantly different.

Our estimates of the economic burden of MetS in patients with hypertension are on the conservative side for a number of reasons. First, no data were available to distribute costs of antihypertensive medications across risk groups and therefore costs have been distributed evenly across each of the five risk groups. Data suggest that the quantity and type of antihypertensive medication does differ between those with and without MetS. Those with MetS use significantly more ACE-inhibitors and ARBs and in general use antihypertensive drugs significantly more frequently than those without the syndrome [17,50]. A redistribution of costs accounting for this would not increase the overall drug costs, but would increase the proportion of drug costs that are attributable to MetS. Second, the number of cardiovascular events occurring in the population was predicted using data derived from a population initially free of cardiovascular disease (a proportion of the population had type 2 diabetes). The model therefore does not take into account the costs attributable to those hypertensive subjects with MetS and established cardiovascular disease, which would increase the total cost of illness. Finally, we only included healthcare costs in our model. Including costs relating to the loss in productivity due to morbidity or premature mortality would inflate costof-illness estimates by between 1.28 fold [51] and 10 fold [52]. Such wide estimates reflect the different methodologies used to calculate productivity losses.

Future prevalence estimates and costs are based on projected changes in the demographics of each country

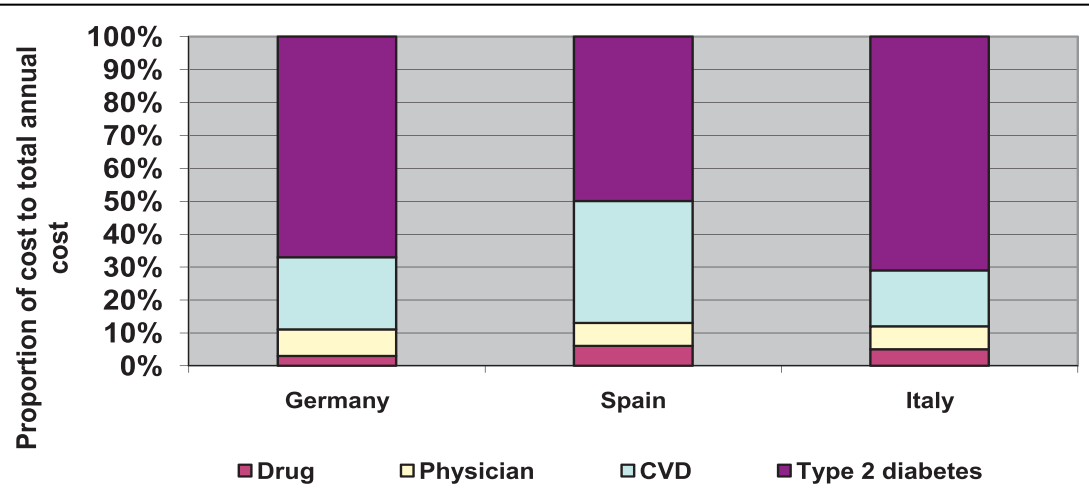

Figure 4 Proportion of drug, physician, cardiovascular and type 2 diabetes costs to total annual costs for patients with hypertension and MetS; 2008. 


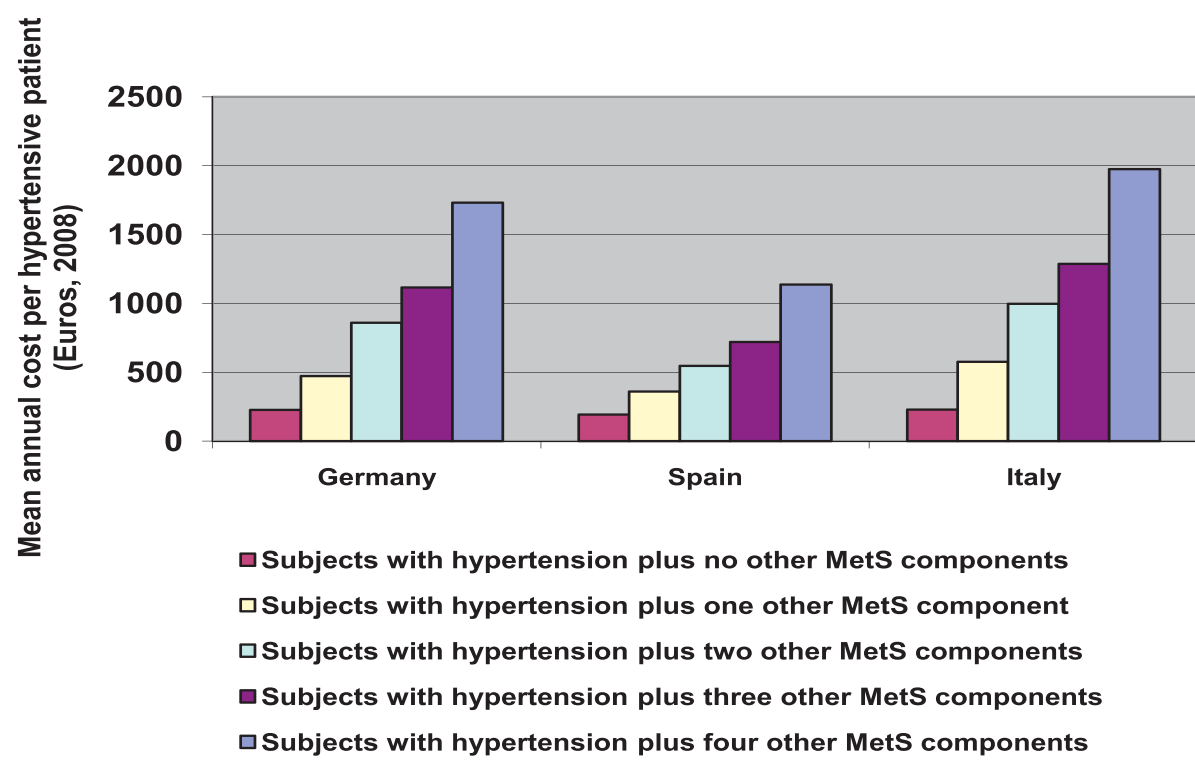

Figure 5 Mean annual costs (Euros) per hypertensive patient according to the number of components of MetS; 2008

and the increase in prevalence of MetS components based on historical data trends. However, such forecasts do not take into account the potential impact of policy directives aimed at reducing the risk of developing one of the five MetS components. Future public health incentives will have an impact on future prevalence and costs however, these policies will be working against an increase in prevalence brought about by the aging population. The burden of illness in the future will therefore be dependent on how effective public health policies and guidelines are at preventing and treating MetS.

A handful of studies have assessed the prevalence of hypertension in patients with MetS, but none to date have assessed its economic impact. Previous population studies using ATP III criteria have shown that approximately $20 \%$ to $40 \%$ of the hypertensive population has MetS [20-23] giving rise to a prevalence in the general population of hypertension and MetS of $8 \%$ to $14 \%$ [20-22]. These estimates are similar to our estimates for Spain and Italy. Much higher estimates of the proportion of hypertensive subjects that have MetS are reported in primary care studies where the variation can be explained in part by the different sub-populations studied $[13,17,24,25,27,53]$.

This study has highlighted the additional resource implications of hypertensive patients with MetS and the need to manage these patients effectively according to European guidelines to reduce the risk of cardiovascular disease and type 2 diabetes. However, a previous European study reported that fewer than $30 \%$ of treated hypertensive patients had their blood pressure controlled to levels recommended by European guidelines and that uncontrolled hypertension was strongly associated with MetS [27]. Not achieving recommended target levels of blood pressure control leaves these patients with elevated levels of risk. The study highlighted the importance of considering the patient's entire cardiometabolic profile when considering appropriate treatment rather than focusing solely on blood pressure targets alone [27].

European guidelines advocate that appropriate management of patients with hypertension should be based on their blood pressure level and overall cardiovascular risk profile. Guidelines recognise that due to the different mode of action of these classes, some drug groups are likely to offer greater benefits to different subgroups of patients $[15,54,55]$. In a recent reappraisal of guidelines on hypertension management, they suggest that drug choice should take into account contraindications as well as favourable effects in specific clinic settings. The guidelines do not recommend specific drugs for the treatment of hypertensive patients with metabolic syndrome, but do point out that 'there is no doubt that beta-blockers and diuretics (especially when combined together) have adverse metabolic effects and facilitate new onset diabetes in predisposed patients such as those with metabolic syndrome or impaired glucose tolerance.' They go on to point out that there is still controversy over whether drug-induced new onset diabetes carries the same negative prognosis as naturally occurring diabetes [55]. In patients with diabetes the guidelines suggest that combination treatment is usually required and that 'a renin-angiotensin receptor blocker should always be included because of the evidence of its superior 
Table 3 Sensitivity analysis, total annual cost-of-illness (Euros, millions) of hypertension in the presence and absence of MetS; 2008

\begin{tabular}{|c|c|c|c|}
\hline & Germany & Spain & Italy \\
\hline \multicolumn{4}{|l|}{ Baseline } \\
\hline Presence & 24,427 & 1,908 & 4,877 \\
\hline Absence & 5,341 & 2,683 & 5,956 \\
\hline \multicolumn{4}{|c|}{ Type 2 diabetes; including only incident type 2 diabetes } \\
\hline Presence & 8,753 & 1,050 & 1,775 \\
\hline Absence & 3,382 & 2,115 & 3,876 \\
\hline \multicolumn{4}{|c|}{ Proportion treated; assume 58\% hypertensive subjects were treated in Spain } \\
\hline Presence & NA & 2,010 & NA \\
\hline Absence & NA & 3,058 & NA \\
\hline \multicolumn{4}{|c|}{ Continuation rate; vary by $20 \%$ above/below the mean } \\
\hline$+20 \%$ Presence & 24,418 & 1,913 & 4,895 \\
\hline$+20 \%$ Absence & 5,357 & 2,707 & 6,035 \\
\hline - 20\% Presence & 24,406 & 1,898 & 4,850 \\
\hline - 20\% Absence & 5,302 & 2,635 & 5,831 \\
\hline \multicolumn{4}{|c|}{$\begin{array}{l}\text { Costs; vary by } 20 \% \text { above/below the mean } \\
\text { Drug costs }\end{array}$} \\
\hline$+20 \%$ Presence & 24,553 & 1,928 & 4,929 \\
\hline$+20 \%$ Absence & 5,423 & 4,329 & 6,147 \\
\hline - 20\% Presence & 24,247 & 1,886 & 4,825 \\
\hline - 20\% Absence & 5,224 & 2,603 & 5,762 \\
\hline \multicolumn{4}{|l|}{ CVD costs } \\
\hline$+20 \%$ Presence & 25,481 & 2,049 & 5,041 \\
\hline$+20 \%$ Absence & 5,682 & 2,934 & 6,276 \\
\hline - 20\% Presence & 23,373 & 1,769 & 4,714 \\
\hline - 20\% Absence & 5,000 & 2,431 & 5,637 \\
\hline \multicolumn{4}{|l|}{ Type 2 diabetes costs } \\
\hline$+20 \%$ Presence & 27,743 & 2,102 & 5,573 \\
\hline$+20 \%$ Absence & 5,735 & 2,803 & 6,392 \\
\hline - 20\% Presence & 21,112 & 1,715 & 4,183 \\
\hline - 20\% Absence & 4,948 & 2,564 & 5,521 \\
\hline
\end{tabular}

protective effect against initiation or progression of nephropathy.'

Evidence suggests that newer antihypertensive medications are associated with a reduced risk of incident diabetes [39] and that they are also associated with better adherence to therapy $[38,56,57]$. Although meta-analyses suggest antihypertensive drugs have a similar effect on reducing cardiovascular events [58], there is some evidence to suggest that newer antihypertensive medications may lead to a greater reduction in the risk of first hypertension-related cardiovascular or diabetic event [57]. In addition, it has been recently demonstrated that obese hypertensive patients under drug-based weight loss therapy show significantly better weight reduction and improvement of insulin resistance when treated with newer antihypertensive medications compared to the older blood pressure lowering drugs (beta blocker, diuretics) [59]. Of the newer antihypertensive treatments ARBs have been found to be associated with the highest level of adherence $[38,56,57]$ and the lowest association with incident diabetes [39]. Furthermore specific ARBs have also demonstrated favourable metabolic effects not present in other ARBs or ACE-inhibitors [60].

Following such guidelines which recommend the aggressive management of these high risk patients with a combination of lifestyle interventions to treat the MetS components present in the hypertensive individual and to prevent the onset of additional components is likely to lead to a significant reduction in costs of care. Newer antihypertensives lead to better control of blood pressure in part brought about by better adherence, thereby reducing the risk of cardiovascular disease. They also reduce the risk of new onset type 2 diabetes. Such outcomes are associated with significant associated costs. Therefore, in patients with hypertension and MetS, some of the drug costs of newer antihypertensive medications will be balanced by costs saved from reducing these negative outcomes. The magnitude of these 
savings is likely to depend on risk group. Patients with hypertension and four other components of MetS will demonstrate greater reductions in the incidence of cardiovascular events and new cases of type 2 diabetes and their associated costs as a result of treatment with newer antihypertensives compared to patients with hypertension only. Cost-effectiveness studies, assessing long-term costs and outcomes, will be required to demonstrate the incremental costs and benefits of new versus old antihypertensives for patients with hypertension and MetS. Studies have already demonstrated the cost-effectiveness of ARBs and ACE-inhibitors in patients at increased risk of diabetes and heart failure [54].

\section{Conclusion}

The results of this study show that hypertensive patients with MetS are associated with higher costs of care compared to those without due to the increase in incident cardiovascular events and prevalent cases of type 2 diabetes. The resource implications of MetS rise linearly with each additional MetS component. This burden is forecast to rise in the future as a result of the aging population and an increase in the components of the syndrome. Prevention and appropriate treatment of MetS is likely to lead to a reduction in costs of care. Newer antihypertensive medications provide better control of blood pressure leading to reduced incidence of cardiovascular disease and type 2 diabetes. These benefits will be more marked in those hypertensive subjects who have a high number of MetS components clustered together. Following guidelines set out for this special group of patients, which advocate the use of newer antihypertensives, are likely to lead to longer-term economic benefits for the health service and quality of life improvement for patients.

\section{List of abbreviations}

ACE: Angiotensin Converting Enzyme; ARB: Angiotensin II receptor blocker; ATP III: Adult Treatment Panel III of the United States National Cholesterol Education Program; CAGR: compound annual growth rate; HDL: high density lipoprotein; MetS: metabolic syndrome; NHANES: (United States) National Health and Nutritional Examination Survey.

\footnotetext{
Author details

'Department of Medicine, Outpatient Clinic, CCM, ChariteUniversitatsmedizin Berlin, Luisenstrasse 11-13, 10117 Berlin, Germany. ${ }^{2}$ Servicio de Cardiología, Policlínica Gipuzkoa, San Sebastián, Spain. ${ }^{3}$ Professor of Internal Medicine, Department of Internal Medicine and Public Health, Division of Internal Medicine, Hypertension \& Cardiovascular Prevention Center, University of L'Aquila, San Salvatore Hospital, L'Aquila, Italy. ${ }^{4}$ Independent Health Economist, Manchester, UK. Independent Health Economist, Boston, USA. ${ }^{6}$ Head of Statistics and Data Management, MRC Tropical Disease Research Unit, Banjul, Gambia. 'Bayer Schering Pharma AG, Global Health Economics \& Outcomes Research, Berlin, Germany.
}

\section{Authors' contributions}

$\mathrm{KU}, J \mathrm{~S}, \mathrm{EA}, \mathrm{CF}, \mathrm{SL}, \mathrm{WS}$ and $\mathrm{DJ}$ were involved in conception and design. SL, WS and DJ were involved in the acquisition of data and analysis. KU, JS, EA and CF were involved in interpretation of data. SL, WS and DJ drafted the manuscript. KU, JS, EA and CF were involved in revising it critically for important intellectual content. All authors approved the final version to be published.

\section{Competing interests}

This project was funded by Bayer Schering Pharma AG.

Received: 11 February 2010 Accepted: 2 September 2010

Published: 2 September 2010

\section{References}

1. Lawes CM, Vander HS, Rodgers A: Global burden of blood-pressurerelated disease, 2001. Lancet 2008, 371:1513-1518.

2. Groves T: Pandemic obesity in Europe. BMJ 2006, 333, 1081-1 com.

3. Krauss RM, Winston M, Fletcher RN, Grundy SM: Obesity: impact of cardiovascular disease. Circulation 1998, 98:1472-1476.

4. Redon J, Cifkova R, Laurent S, Nilsson P, Narkiewicz K, Erdine S, et al: Mechanisms of hypertension in the cardiometabolic syndrome. J Hypertens 2009, 27:441-451.

5. Ford ES: Risks for all-cause mortality, cardiovascular disease, and diabetes associated with the metabolic syndrome: a summary of the evidence. Diabetes Care 2005, 28:1769-1778.

6. Galassi A, Reynolds K, He J: Metabolic syndrome and risk of cardiovascular disease: a meta-analysis. Am J Med 2006, 119:812-819.

7. Sattar N, Gaw A, Scherbakova O, Ford I, O'Reilly DS, Haffner SM, et al: Metabolic syndrome with and without C-reactive protein as a predictor of coronary heart disease and diabetes in the West of Scotland Coronary Prevention Study. Circulation 2003, 108:414-419.

8. Isomaa B, Almgren P, Tuomi T, Forsen B, Lahti K, Nissen M, et al: Cardiovascular morbidity and mortality associated with the metabolic syndrome. Diabetes Care 2001, 24:683-689.

9. Schillaci G, Pirro M, Pucci G, Mannarino MR, Gemelli F, Siepi D, et al: Different impact of the metabolic syndrome on left ventricular structure and function in hypertensive men and women. Hypertension 2006, 47:881-886.

10. Andreadis EA, Tsourous GI, Tzavara CK, Georgiopoulos DX, Katsanou PM, Marakomichelakis GE, et al: Metabolic syndrome and incident cardiovascular morbidity and mortality in a Mediterranean hypertensive population. Am J Hypertens 2007, 20:558-564.

11. Pierdomenico SD, Lapenna D, Di Tommaso R, Di Carlo S, Caldarella MP, Neri M, et al: Prognostic Relevance of Metabolic Syndrome in Hypertensive Patients at Low-to-Medium Risk. Am J Hypertens 2007, 20:1291-1296.

12. Segura J, Banegas JR, Garcia-Donaire JA, Rodriquez-Artalejo F, de la Cruz JJ, Praga $M$, et al: Should hypertension guidelines be changed for hypertensive patients with the metabolic syndrome? I Clin Hypertens (Greenwich) 2007, 9:595-600.

13. Schillaci G, Pirro M, Vaudo G, Gemelli F, Marchesi S, Porcellati C: Prognostic value of the metabolic syndrome in essential hypertension. J Am Coll Cardiol 2004, \%19(43):1817-1822.

14. Stamler J, Vaccaro O, Neaton JD, Wentworth D: Diabetes, other risk factors, and 12-yr cardiovascular mortality for men screened in the Multiple Risk Factor Intervention Trial. Diabetes Care 1993, 16:434-444.

15. Mancia G, De Backer G, Dominiczak A, Cifkova R, Fagard R, Germano G, et al: 2007 Guidelines for the management of arterial hypertension: The Task Force for the Management of Arterial Hypertension of the European Society of Hypertension (ESH) and of the European Society of Cardiology (ESC). Eur Heart J 2007, 28:1462-1536.

16. Redon J, Cifkova R, Laurent S, Nilsson P, Narkiewicz K, Erdine S, et al: The metabolic syndrome in hypertension: European society of hypertension position statement. J Hypertens 2008, 26:1891-1900.

17. Barrios V, Escobar C, Calderon A, Llisterri JL, Alegria E, Muniz J, et al: Prevalence of the metabolic syndrome in patients with hypertension treated in general practice in Spain: an assessment of blood pressure 
and low-density lipoprotein cholesterol control and accuracy of diagnosis. J Cardiometab Syndr 2007, 2:9-15.

18. de la SA, Romero R, Bonet J, Perez M, Lopez JS, Ravella R, et al: [Prevalence and general features of the metabolic syndrome in the Spanish hypertensive population]. Med Clin (Barc) 2006, 126:406-409.

19. Assmann G, Guerra R, Fox G, Cullen P, Schulte H, Willett D, et al: Harmonizing the definition of the metabolic syndrome: comparison of the criteria of the Adult Treatment Panel III and the International Diabetes Federation in United States American and European populations. Am J Cardiol 2007, 99:541-548.

20. Cordero A, Laclaustra M, Leon M, Grima A, Casasnovas JA, Luengo E, et al: Prehypertension is associated with insulin resistance state and not with an initial renal function impairment. A Metabolic Syndrome in Active Subjects in Spain (MESYAS) Registry substudy. Am J Hypertens 2006, 19:189-196.

21. Ferrara LA, Cardoni O, Mancini M, Zanchetti A: Metabolic syndrome and left ventricular hypertrophy in a general population. Results from the Gubbio Study. J Hum Hypertens 2007, 21:795-801.

22. Mancia G, Parati G, Borghi C, Ghironzi G, Andriani E, Marinelli L, et al: Hypertension prevalence, awareness, control and association with metabolic abnormalities in the San Marino population: the SMOOTH study. J Hypertens 2006, 24:837-843.

23. Mancia G, Bombelli M, Corrao G, Facchetti R, Madotto F, Giannattasio C, et al: Metabolic syndrome in the Pressioni Arteriose Monitorate E Loro Associazioni (PAMELA) study: daily life blood pressure, cardiac damage, and prognosis. Hypertension 2007, 49:40-47.

24. Romero R, Bonet J, de la SA, Aguilera MT, Esopoh SI: Undiagnosed obesity in hypertension: clinical and therapeutic implications. Blood Press 2007, 16:347-353.

25. Navarro J, Redon J, Cea-Calvo L, Lozano JV, Fernandez-Perez C, Bonet A, et al: Metabolic syndrome, organ damage and cardiovascular disease in treated hypertensive patients. The ERIC-HTA study. Blood Press 2007, 16:20-27.

26. de la SA, Romero R, Bonet J, Perez M, Lopez JS, Ravella R, et al: [Prevalence and general features of the metabolic syndrome in the Spanish hypertensive population]. Med Clin (Barc) 2006, 126:406-409.

27. Kjeldsen SE, Naditch-Brule L, Perlini S, Zidek W, Farsang C: Increased prevalence of metabolic syndrome in uncontrolled hypertension across Europe: the Global Cardiometabolic Risk Profile in Patients with hypertension disease survey. J Hypertens 2008, 26:2064-2070.

28. Wille E, Scholze J, Alegria E, Ferri C, Langham S, Stevens W, et al: Modelling the costs of care of hypertension in patients with metabolic syndrome and its consequences, in Germany, Spain and Italy. Eur J Health Econ 2010.

29. Expert Panel on Detection EaToHBCiA: Third Report of the National Cholesterol Education Program (NCEP) Expert Panel on Detection, Evaluation, and Treatment of High Blood Cholesterol in Adults (Adult Treatment Panel III) final report. Circulation 2002, 106:3143-3421.

30. Chobanian AV, Bakris GL, Black HR, Cushman WC, Green LA, Izzo JL Jr, et al: The Seventh Report of the Joint National Committee on Prevention, Detection, Evaluation, and Treatment of High Blood Pressure: the JNC 7 report. JAMA 2003, 289:2560-2572.

31. Robert Koch Institute: Public Use File BGS98, German National Health Interview and Examination Survey 1998. Berlin (Germany), Robert Koch Institute 2000.

32. Perez-Fernandez R, Marino AF, Cadarso-Suarez C, Botana MA, Tome MA, Solache I, et al: Prevalence, awareness, treatment and control of hypertension in Galicia (Spain) and association with related diseases. J Hum Hypertens 2007, 21:366-373.

33. Mancia G, Volpe R, Boros S, llardi M, Giannattasio C: Cardiovascular risk profile and blood pressure control in Italian hypertensive patients under specialist care. J Hypertens 2004, 22:51-57.

34. Datamonitor: Stakeholder Insight: Metabolic Syndrome. Delaney, A, Fleetwood, and A. New York., Datamonitor 2004.

35. Gandjour A, Stock S: A national hypertension treatment program in Germany and its estimated impact on costs, life expectancy, and costeffectiveness. Health Policy 2007, 83:257-267.

36. Rovira J, Badia X, Pardell H: Cost of hypertension in Spain. J Hum Hypertens 1992, 6:481-483.
37. Degli EE, Berto P, Ruffo P, Buda S, Degli EL, Sturani A: The PANDORA project: results of the cost of illness analysis. J Hum Hypertens 2001, 15:329-334.

38. Esposti LD, Di Martino M, Saragoni S, Sgreccia A, Capone A, Buda S, et al: Pharmacoeconomics of antihypertensive drug treatment: an analysis of how long patients remain on various antihypertensive therapies. $J$ Clin Hypertens (Greenwich) 2004, 6:76-84

39. Elliott WJ, Meyer PM: Incident diabetes in clinical trials of antihypertensive drugs: a network meta-analysis. Lancet 2007, \% 20(369):201-207.

40. Hansson L, Lloyd A, Anderson P, Kopp Z: Excess morbidity and cost of failure to achieve targets for blood pressure control in Europe. Blood Press 2002, 11:35-45.

41. Breekveldt-Postma NS, Penning-van Beest FJ, Siiskonen SJ, Falvey H, Vincze $\mathrm{G}$, Klungel $\mathrm{OH}$, et al: The effect of discontinuation of antihypertensives on the risk of acute myocardial infarction and stroke. Curr Med Res Opin 2008, 24:121-127.

42. Noto D, Barbagallo CM, Cefalu AB, Falletta A, Sapienza M, Cavera G, et al: The metabolic syndrome predicts cardiovascular events in subjects with normal fasting glucose: results of a 15 years follow-up in a Mediterranean population. Atherosclerosis 2008, 197:147-153.

43. Mar J, Rodriguez-Artalejo F: Which is more important for the efficiency of hypertension treatment: hypertension stage, type of drug or therapeutic compliance? J Hypertens 2001, 19:149-155.

44. Taylor MJ, Scuffham PA, McCollam PL, Newby DE: Acute coronary syndromes in Europe: 1-year costs and outcomes. Curr Med Res Opin 2007, 23:495-503.

45. Mullins CD, Sikirica M, Seneviratne V, Ahn J, Akhras KS: Comparisons of hypertension-related costs from multinational clinical studies. Pharmacoeconomics 2004, 22:1001-1014.

46. Jonsson B: Revealing the cost of Type II diabetes in Europe. Diabetologia 2002, 45:S5-12.

47. International Association for the Study of Obesity: Adult overwieght and obesity in EU 27. 2009 [http://www.iotf.org/database/documents/ AdultEU27March2010notonwebyetupdatev2.pdf].

48. Berghofer A, Pischon T, Reinhold T, Apovian CM, Sharma AM, Willich SN: Obesity prevalence from a European perspective: a systematic review. BMC Public Health 2008, 8(200), schemas-com.

49. Neuhauser $\mathrm{H}$, Ellert $\mathrm{U}$ : Estimation of the metabolic syndrome prevalence in the general population in Germany. J Public Health 2008, 16:221-227.

50. de la SA, Romero R, Bonet J, Perez M, Lopez JS, Ravella R, et al: [Prevalence and general features of the metabolic syndrome in the Spanish hypertensive population]. Med Clin (Barc) 2006, 126:406-409.

51. Maetzel A, Li LC, Pencharz J, Tomlinson G, Bombardier C: The economic burden associated with osteoarthritis, rheumatoid arthritis, and hypertension: a comparative study. Ann Rheum Dis 2004, 63:395-401.

52. Kiiskinen U, Vartiainen E, Puska P, Aromaa A: Long-term cost and lifeexpectancy consequences of hypertension. J Hypertens 1998, 16:1103-1112.

53. de la SA, Romero R, Bonet J, Perez M, Lopez JS, Ravella R, et al: [Prevalence and general features of the metabolic syndrome in the Spanish hypertensive population]. Med Clin (Barc) 2006, 126:406-409.

54. National Institute for Health and Clinical Excellence: CG34: Hypertension: NICE clinical guidelines. London, UK, National Institute for Health and Clinical Excellence 2006.

55. Mancia G, Laurent S, Agabiti-Rosei E, Ambrosioni E, Burnier M, Caulfield MJ, et al: Reappraisal of European guidelines on hypertension management: a European Society of Hypertension Task Force document. Blood Press 2009, 18:308-347.

56. Corrao G, Zambon A, Parodi A, Poluzzi E, Baldi I, Merlino L, et al: Discontinuation of and changes in drug therapy for hypertension among newly-treated patients: a population-based study in Italy. J Hypertens 2008, 26:819-824.

57. Mathes J, Kostev K, Gabriel A, Pirk O, Schmieder RE: Risks and costs of the first hypertension-associated event, compliance and persistence in niave hypertensive patients after initiating monotherapy. Value Health 2008, 11.

58. Law MR, Morris JK, Wald NJ: Use of blood pressure lowering drugs in the prevention of cardiovascular disease: meta-analysis of 147 randomised trials in the context of expectations from prospective epidemiological studies. BMJ 2009, 338:b1665. 
59. Scholze J, Grimm E, Herrmann D, Unger T, Kintscher U: Optimal treatment of obesity-related hypertension: the Hypertension-Obesity-Sibutramine (HOS) study. Circulation 2007, 115:1991-1998.

60. Kurtz TW: New treatment strategies for patients with hypertension and insulin resistance. Am J Med 2006, 119:S24-S30.

Pre-publication history

The pre-publication history for this paper can be accessed here: http://www.biomedcentral.com/1471-2458/10/529/prepub

doi:10.1186/1471-2458-10-529

Cite this article as: Scholze et al.: Epidemiological and economic burden of metabolic syndrome and its consequences in patients with

hypertension in Germany, Spain and Italy; a prevalence-based model.

BMC Public Health 2010 10:529.

Submit your next manuscript to BioMed Central and take full advantage of:

- Convenient online submission

- Thorough peer review

- No space constraints or color figure charges

- Immediate publication on acceptance

- Inclusion in PubMed, CAS, Scopus and Google Scholar

- Research which is freely available for redistribution

Submit your manuscript at www.biomedcentral.com/submit
C Biomed Central 